\title{
Differentiating diverse diets: a novel approach to analyzing cafeteria feeding trials
}

\author{
Michael Cramer ${ }^{1}$, Amy Le Blanc ${ }^{1}$, David Flagel ${ }^{1}$, and Samantha Driscoll ${ }^{2}$ \\ ${ }^{1}$ University of Notre Dame \\ ${ }^{2}$ Syracuse University
}

June 1, 2020

\begin{abstract}
Foraging decisions are essential for survival, thus investigation of food preferences is a major goal in behavioral ecology. Cafeteria trials, in which multiple options are displayed to foragers simultaneously, can quantify these preferences. However, statistical analyses of these data are problematic. The aim of this research is to determine the efficacy of using Shannon Diversity $\left(H_{s}\right)$ and Evenness $(J)$ to quantify diet preferences and apply this approach to field data collected in a model system. Shannon Diversity $\left(H_{s}\right)$ provides a single value to represent a forager's diet, based on proportions of each food type offered. Shannon Evenness $(J ')$ assesses the relative quantity of each food type consumed, and is an intuitive way to address foraging preferences. Null models inspected how values of $H_{s}$ and $J^{\prime}$ change with diet breadth. This approach was tested for a cafeteria trial of two common chipmunks [Eastern (Tamias striatus) and Least (Neotamias minimus)] with five different seed types [Red (Acer rubrum) and Sugar (A. saccharum) Maple, Balsam Fir (Abies balsamea), Pin Cherry (Prunus pensylvanica), and Beaked Hazelnut (Corylus cornuta)]. Hypothesis tests determined if observed diets were statistically different from those predicted based on equal preferences. Values of $H_{s}$ increased with diet breadth; although mean $J$ ' was unaffected by diet breadth, variability increased. Chipmunks displayed significant seed preferences: Tamias preferred Sugar Maple whereas Neotamias preferred Red Maple. Moreover, each species avoided the seed type preferred by the other chipmunk. Null models indicate that $H_{s}$ accurately estimates real changes in diet breadth. The fact that $J$ ' did not significantly change with increasing diet breadth also supports the utility of this approach to determine non-random diet preferences. Use of diversity indices to quantify feeding choices can be extended to other contexts (e.g., comparison of suites of foragers, and altering feeding context by changing amounts of each resource offered).
\end{abstract}

\section{Introduction}

Foraging decisions are essential because they directly affect survival through nutrient and energy acquisition (Sih, 2011). In most cases, foragers choose from a variety of food options. Many factors affect these choices including differences in availability and accessibility. Understanding the factors that affect these decisions provides insight into how animals budget their time in addition to the selective pressures which shape feeding preferences (Ydenberg, Brown, \& Stephens 2007).

One way researchers document these choices is through cafeteria trials, in which foragers are offered many food items simultaneously (Morrison \& Hik, 2008; Woods 2009; Dostaler, Ouellet, Therrien, \& Côté 2011). Choices made during these trials presumably reflect choices made during normal foraging in the wild. Cafeteria trials allow for direct tests of the balances between energetic costs and benefits because they allow researchers to control some of the variables that affect foraging decisions such as search time and relative abundance of different food types. It is also important to consider the number of options offered in these experiments, as foraging preferences can vary with the diversity of options (Wang, Wang, Liu, Huang, \& Hodgkinson 2011). Moreover, cafeteria trials conducted in the laboratory can control for several environmental variables. 
A wide variety of approaches can discriminate foraging preferences from cafeteria trials (Elston, Illius, \& Gordon 1996). Analysis of preference using pairwise comparisons can be problematic because not only does this oversimplify foraging decisions, but the probability of observing a spurious preference for any food type increases with the number of comparisons (Thomas \& Taylor, 1990). Moreover, ranking foraging preferences based on pairwise comparisons overlooks the importance of the presence of alternative food types on foraging decisions (Woods, 2009). Other problems plague some approaches. For example, if a forager avoids a given resource, this can cause mathematical or computational problems because of zeros in the data (Elston, Illius, \& Gordon 1996). In addition, zeros are a problem for statistical approaches that require chi-square tests to determine preferences (Neu, Byers, \& Peek 1974), as these tests require most expected frequencies to be greater than one (van Emden, 2008).

Resource consumption curves provide an excellent approach to measuring foraging preferences (Krebs, 1999). Foragers are monitored over time to determine how much resource is consumed in the absence of other resources. The utility of the consumption curve is dependent on the time scale of measurement of the amount consumed. Measuring consumption too often may interrupt or negatively affect foraging behavior, introducing a bias into the analysis. Also, this index assumes preferences are additive and there is no interaction between different resource types.

The preferable approach to analyzing data from cafeteria trials is to develop an index that incorporates preferences across many food types simultaneously. The Shannon Diversity Index accomplishes this task. Considering each food item, the index quantifies not only the number of food types in the diet (analogous to species richness) but also the distribution of food items within each food type (analogous to evenness). Species diversity is useful if foragers avoid certain food types, but evenness is preferable if foragers sample all food types available, and provides the most information concerning feeding preferences. Given a starting amount of resources, a null hypothesis of equal preference can be calculated and compared to the observed value with a simple hypothesis test. One shortcoming of the index is that is only indicates if a preference exists but does not allow for identification of which food type is preferred without further testing. It does, however, allow comparisons between groups of individuals (i.e., different species, males versus females, etc.) and could be applied to any amount of $n$ food types. Its simplicity is also a benefit.

This study assesses the efficacy of using Shannon diversity indices to test hypotheses concerning foraging preferences. When foragers include more resources in their diets, or increase their diet breadth, this should be reflected by higher values of the Shannon Diversity index $\left(H_{s}\right)$. Nuanced differences in diets can be determined by testing evenness, or the distribution of selected food items into different resource categories. In the case of equal preferences for all food types, values of Shannon Evenness $\left(J^{\prime}\right)$ should be unaffected by diet breadth. This interpretation of Evenness provides an excellent null model, as it assumes the complete lack of partial preferences (Stephens \& Krebs 1986), and generates a single value to compare to actual diets. Null models demonstrated how the indices reacted to changes in diet breadth, and field preferences were tested using data generated from a series of cafeteria trials on common forest granivores.

Forest granivores provide an excellent model system to address questions about foraging decisions. Seeds are a convenient resource for representing the variety of food items occurring in natural environments because they are ubiquitous, easily measured, and readily manipulated. Moreover, studying seed consumption can lead to insights about how granivores may affect forest composition through their foraging decisions (Meiners \& Stiles, 1997; Lobo, Green, \& Millar 2013). Foragers encounter many different seed types leading to speciesspecific preferences. For example, deer mice demonstrate divergent seed preferences: the woodland deer mouse (Peromyscus maniculatus gracilis ), shows a strong preference for red maple (Acer rubrum) over sugar maple (A. saccharum) seeds, while the seed preferences of the white-footed deer mouse ( $P$. leucopus ) are less clear (Cramer, 2014). In the Great Lakes region, two common and well-studied seed predators are eastern chipmunks (Tamias striatus ) and least chipmunks (Neotamias minimus ) (Hsia \& Francl, 2009; Myers, Lundrigan, Hoffman, Haraminac, \& Seto 2009; Penner \& Devenport, 2011; Jenkins \& Devenport, 2014).

Ecological differences between these species should lead to differential foraging preferences. T. striatus is 
a habitat generalist (Snyder, 1982) and is more common in the rodent community than N. minimus, a habitat specialist that prefers mesic areas (Verts \& Carraway, 2001). There is also a distinctive body size difference: $N$. minimus is approximately half the mass of T. striatus . In addition, there are behavioral differences between these chipmunks:T. striatus can be active year-round and are larder hoarders, whereas N. minimus undergoes seasonal torpor in the winter months and stores seeds in small dispersed caches.

Regardless of these differences, studies in other systems with multiple species of chipmunk have demonstrated prevalent interspecific competition. This may be ameliorated in Great Lakes forests by limiting similarity, in which foraging choices between similar species is mediated by seed size. Granivores differentially harvest seeds of different sizes, and the size of seed selected for is positively correlated with body size [Brown \& Lieberman, 1973; Emmons, 1980). Small seeds may not provide enough energy for larger granivores to survive, but smaller seeds are more accessible to smaller granivores. Thus, it is reasonable to expect that differential seed preferences between these species are based on seed size.

Two sets of hypotheses were generated for the null model analysis and the field-test using actual recorded diets. For the null model, we predicted that the value of the Shannon index would increase as more food types were added to the diet, but that Evenness would remain constant regardless of diet breadth. For the chipmunk model system, we predicted that each species would demonstrate partial preferences based on seed size: T. striatus should select larger seeds and N. minimus select small seeds.

\section{Methods}

Null models were constructed in R (R Core Team, 2019). The resource base comprised ten types of food, and foragers would randomly select up to ten items of each food type. Foragers could select zero items for any of the food types, and these were eliminated prior to calculation of the Shannon Index, and allowed for variation in diet breadth. Models were run for 1000 iterations, and it was noted that diet breadth was always greater than five items; stenophagic diets were excluded from analysis due to stochastic factors. Thus, the model was altered to allow for more variation in diet breadth: the diet breadth (analogous to species richness) was a random number between two and 10 and the food item selection was constrained to fit this number of different types of food items. A further constraint was eliminating complete specialist diets (where the diet breadth was one). This allowed calculation of Shannon Evenness: complete specialist diets have no evenness, as all food items are of the same type. So the final model selected food items (between one and 10) for a random number of food types (between two and 10). Shannon Diversity and Evenness were calculated, and this process was iterated 1000 times. These data were analyzed to determine how diet breadth affects Shannon Diversity and Evenness.

The proportion of each food type consumed $\left(p_{i}\right)$ was calculated by dividing the number of food items of that particular type by the total number of all food items consumed. These proportions allowed calculation of the Shannon Diversity index $\left(H_{s}\right)$,

$$
H_{S}=-\sum_{i=1}^{S} p_{i} \log p_{i}
$$

where $S$ is the total number of food types (Maurer \& McGill, 2011). In cases where individuals consume portions of every species offered, analysis of evenness provides additional information. Shannon Evenness Index $\left(J^{\prime}\right)$ was calculated by dividing $H_{s}$ by the natural $\log$ of $S$ (Maurer \& McGill, 2011).

The field study was conducted at the University of Notre Dame Environmental Research Center (UNDERC), located on the southwestern border of the Upper Peninsula of Michigan near Land O'Lakes, Wisconsin. Data for T. striatus were collected from May-July 2012, and data for N. minimus were collected in May-July 2013. We assumed that foraging preferences would not vary significantly between years, and that any observed differences in foraging behavior were species-specific. Because these preferences were tested in a laboratory setting using seeds obtained from a commercial supplier, the availability of seeds was constant and variation in seed quality was presumably reduced. Moreover, the trial methodology used in both years was identical. 
Chipmunks were trapped using Sherman and Tomahawk traps baited with apples and peanut butter. Any pregnant or lactating females were released immediately at the site of capture and were not used in the study. Once captured, each chipmunk was placed in a glass aquarium with a plywood cover in the laboratory. The bottom of the aquarium was covered in shaved cedar bedding and a plastic container was present with polyfill bedding for nesting. A cloth covered three sides of the aquarium so the chipmunk was not disturbed by other activities in the room during the trial. The open side of the aquarium was placed near a window to allow natural light to enter throughout the day. Striped sunflower seeds and water were available ad libitum during an acclimation period which lasted from the time of capture until $2200 \mathrm{~h}$ of the same day. The use of animals in this study followed the guidelines of the Animal Behavior Society (Ethical and Animal Care Committee of the Animal Behavior Society, 2012) and the American Society of Mammologists (Sikes \& Gannon, 2011).

Seed preferences were determined using cafeteria-style feeding trials, which have been used in previous studies to accurately represent the actual food habits of small mammals (Page, Swihart, \& Kazacos 2001; Lobo, Duong, \& Millar 2009). At 2200h on the day of capture, the sunflower seeds were removed followed by an 8 hour overnight starvation period. Because chipmunks are diurnal, the subjects should have been inactive for most of the starvation period (Lobo, Duong, \& Millar 2009). The starvation period ended at $0600 \mathrm{~h}$ the following morning with the introduction of the trial seeds: sugar maple $(A$ saccharum $)$, beaked hazelnut (Corylus cornuta), red maple (A r rubrum), balsam fir (Abies balsamea), and pin cherry (Prunus pensylvanica), representing some of the most common woody species in the area (Curtis, 1959). Due to significant size differences, T. striatus were given twenty grams of each seed species and N. minimus were given ten grams of each for a total of $100 \mathrm{~g}$ and $50 \mathrm{~g}$ of food offered, respectively. The seeds were placed in an open container such that all were equally available to the chipmunk. At $1800 \mathrm{~h}$, twelve hours after the introduction of the seeds, the seeds were removed. The chipmunk was then released at the site of capture. Eleven $N$. minimus and fourteen T. striatus were used during this study.

The seeds remaining, both in the food container and among the bedding, were separated by species. The final mass of each seed species was measured and was subtracted from the initial seed mass to determine the total amount of each seed species consumed. During the N. minimustrials, some seed species gained mass during the trial. This was likely due to high humidity, so we conservatively assumed no seeds of that species were consumed during that trial. The probability that this strongly biased the analysis is low, as this only occurred in three of the trials.

The expected values of $H_{s}$ and $J$ ' for the proportion of seed species consumed were calculated assuming no seed preference (i.e. the chipmunk ate the same amount of each seed, $p_{i}=0.20$ ). These values were compared with a simple hypothesis test to the mean $H_{s}$ and $J^{\prime}$ calculated across all trials for each chipmunk species. Hypothesis tests between the measured values of the Shannon Diversity and Evenness Index and the expected values would show if the chipmunks display a seed preference.

Specific seed preferences would then be determined with repeated measures analysis of variance (RMANOVA) that compared the proportion consumed of each food type by chipmunk species. Repeated measures tests were used because the consumption of one seed species is not independent of the consumption of another seed species since all five food types were introduced at the same time. The results of this test would show if seed preferences were consistent between chipmunk species.

Finally, data were transformed using the logit transformation (Warton \& Hui, 2011) for use in t-tests of each seed type between values of $T$. striatus and $N$. minimus. These tests would more specifically show for which seed species the chipmunks have different preferences. Since there were some values in which the amount consumed, and thus, the proportion consumed, were zero, a small value (0.00000001) was used to represent that resource. Results are reported as means \pm standard errors.

\section{Results}

Model output data were never normally distributed (Shapiro-Wilk - Diversity: $W=0.928, P<0.001$; Evenness: $W=0.781, P<0.001$ ) nor homoscedastic (Bartlett - Diversity: $K^{2}=105.69$, df $=8, P<0.001$; Evenness: $\left.K^{2}=651-64, \mathrm{df}=8, P<0.001\right)$; thus nonparametric tests determined the effect of diet breadth 
on Shannon Diversity and Evenness. Shannon Diversity increased with diet breadth (Kruskal-Wallis: $X^{2}=$ 974.05, df $=8, P<0.001$; Figure 1a) but Shannon Evenness was similar for every diet, regardless of number of food types (Kruskal-Wallis: $X^{2}=13.99$, $\mathrm{df}=8, P=0.08$; Figure $1 \mathrm{~b}$ ). One interesting observation was that variation in values of Evenness decreased with increasing diet breadth. Variability (measured as the coefficient of variation) decreased with increasing diet breadth (linear regression: $F_{1,7}=13.72, P=0.008$, $\left.r^{2}=0.614\right)$. However, the relationship between variability in $J$ ' and diet breadth is non-linear: a reciprocal function provides a better fit between expected and observed values $\left(F_{1,7}=118.8, P<0.001, r^{2}=0.936\right)$. Another interesting observation from the null model analysis is that the value of $J$ ' under the assumption of equal preferences is constant (0.434294) regardless of the number of food types. Thus, the results can be more clearly visualized by using the standardized value (observed value/equal preferences value).

A.

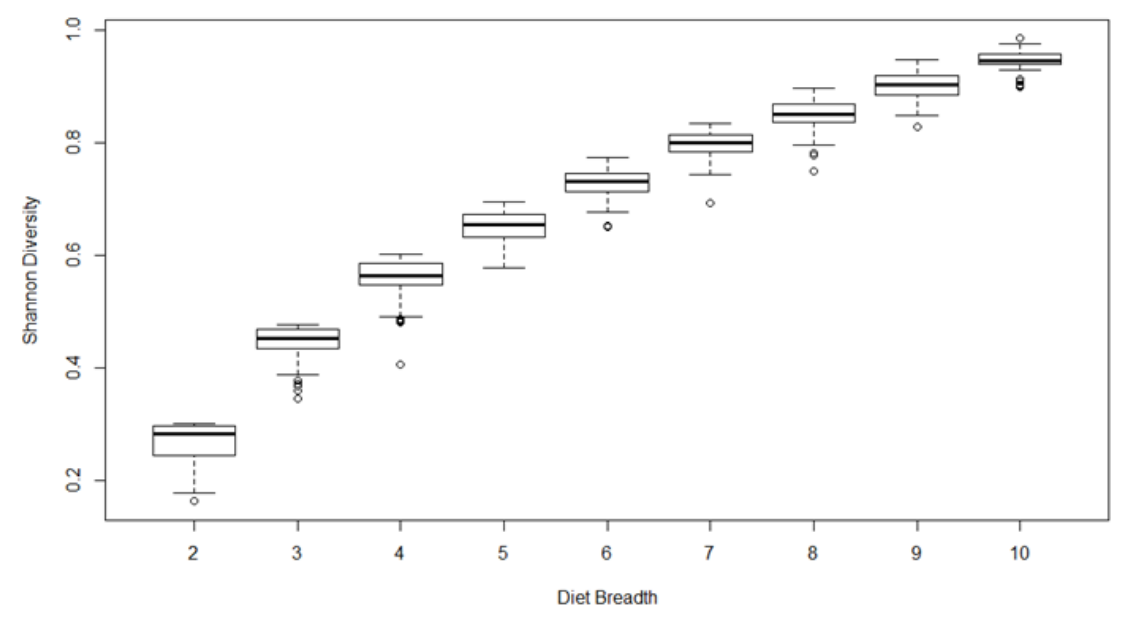

B.

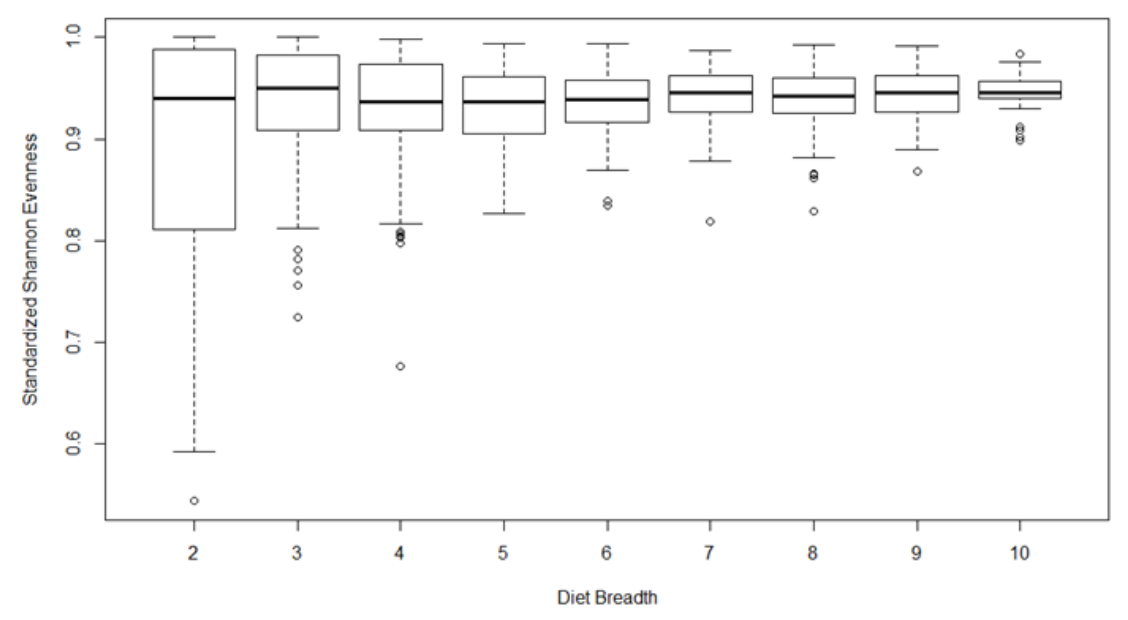

Fig. 1 Results of null model analyses. A. Values of the Shannon Diversity Index increased with increasing diet breadth (Kruskal-Wallis: $X^{2}=974.05, \mathrm{df}=8, P<0.001$ ). B. There was no significant relationship 
between diet breadth and standardized values of Shannon Evenness (Kruskal-Wallis: $X^{2}=13.99$, df $=8, P$ $=0.08)$.

A total of 14 T. striatus and $11 N$. minimus were tested. One $N$. minimus trial was removed from the Evenness analysis because the chipmunk only consumed a small amount of a single seed type, so the value of the Shannon Index was zero, and the Evenness was mathematically undefined. If individuals consumed resources in their offered proportions, we expect the Shannon Diversity Index $\left(H_{s}\right)$ to be 0.70 . In the absence of seed preference, we expect the Shannon Evenness $\left(J^{\prime}\right)$ to be 0.43 . We found that both T. striatus $\left(H_{s}=\right.$ $0.41 \pm 0.03$; One-sample $t$ test: $\left.t_{13}=-10.56, P<0.001\right)$ and $N$. minimus $\left(H_{s}=0.38 \pm 0.06\right.$; One-sample $t$ test: $\left.t_{10}=-4.94, P<0.001\right)$ had values for the Shannon Index that were significantly lower than expected. Similar results were obtained for our analysis of Shannon Evenness (T. striatus : $J^{\prime}=0.28 \pm 0.01$; Onesample $t$ test: $t_{13}=-10.39, P<0.001 ; N$. minimus : $J^{\prime}=0.29 \pm 0.02$, One-sample $t$ test: $t_{9}=-6.02, P<$ 0.001). Both of these results indicate evidence of significant seed preferences by both chipmunk species.

A repeated measures analysis compared the proportion consumed of each seed species between T. striatus and $N$. minimus to account for the fact that the consumption of each seed was not independent in this study. If the species of chipmunk is not accounted for, there is no significant difference between the seed species and proportion consumed (ANOVA: $F_{4,92}=0.73, P=0.57$ ). However, there is a significant interaction between chipmunk species and seed species (ANOVA: $F_{4,92}=16.07, P<0.001$ ). This indicates that the identity of seed consumed the most depends on the chipmunk species, thus confirming the results of the Shannon Evenness t-tests even after accounting for the fact that the consumption of seed species is not independent.

\section{Hosted file}

image2.emf available at https://authorea.com/users/328478/articles/455727-differentiatingdiverse-diets-a-novel-approach-to-analyzing-cafeteria-feeding-trials

Fig. 2 Average proportion of seed species consumed in N. minimusand T. striatus feeding trials. There is a significant difference in proportion of consumed $A$. saccharum seeds $\left(t_{23}=-4.11, P<0.001\right)$ and $A$. rubrum seeds $\left(t_{23}=6.82, P<0.001\right)$. There was not a significant difference in proportion of consumed $A$. balsamea seeds $\left(t_{23}=0.37, P=0.71\right)$ or $P$. pensylvanica seeds $\left(t_{23}=-0.75, P=0.46\right)$. The difference in proportion consumed of $C$. cornuta seeds approach significance $\left(t_{23}=-2.41, P=0.02\right)$.

T-tests compared the proportion consumed of each seed species between T. striatus and N. minimus (Figure 2 ). There was a significant difference in proportion consumed of A. rubrum seeds between T. striatus (0.04 $\pm 0.01)$ and $N$. minimus $\left(0.65 \pm 0.06\right.$; One-sample $t$ test: $\left.t_{23}=6.82, P<0.001\right)$. There was also a significant difference in proportion of consumed $A$. saccharum seeds between T. striatus $(0.34 \pm 0.02)$ and $N$. minimus $\left(0.06 \pm 0.01\right.$; One-samplet test: $\left.t_{23}=-4.11, P<0.001\right)$. There was not a significant difference in proportion of consumed $A$. balsamea seeds between $T$. striatus $(0.09 \pm 0.01)$ and $N$. minimus ( $0.12 \pm 0.01$; One-sample $t$ test: $\left.{ }_{23}=0.37, P=0.71\right)$. There was also not a significant difference in proportion of $P$. pensylvanica seeds consumed between T. striatus $(0.18 \pm 0.01)$ and $N$. minimus $\left(0.11 \pm 0.01\right.$; One-sample $t$ test: $t{ }_{23}=-0.75, P$ $=0.46)$. The difference in proportion consumed of $C$. cornuta seeds between T. striatus $(0.34 \pm 0.02)$ and $N$. minimus $(0.06 \pm 0.01)$ approach significance (One-samplet test: $\left.t_{23}=-2.41, P=0.02\right)$ after a Bonferroni Sequential Adjustment (Rice, 1989).

\section{Discussion}

The observation that the value of the Shannon Index increased with rising number of food types indicates that the index accurately estimates real changes in diet breadth. Moreover, the fact that the values for Shannon Evenness did not significantly change with increasing diet breadth also supports the utility of this approach to determine non-random diet preferences.

The diversity approach for analyzing data collected from cafeteria trials is useful in its simplicity. Statistically, there is increased power by using a simple hypothesis test to determine if foragers are consuming resources in the same proportion in which they encounter them. One shortcoming is that this analysis will only detect that preferences exist but cannot provide further information about specific preferences, which requires 
additional testing. The diversity index can test for diet differences among species, but can be misleading, as the data collected for this study demonstrate. For example, although the mean Shannon Evenness value for N. minimus (0.29) is statistically identical to that for T. striatus (0.28), their foraging preferences are actually highly divergent. The reason for the similarity in index values is that the resources avoided by one species are the ones preferred by the other (i.e., these species have complimentary foraging preferences). Specifically, A. rubrum was avoided by T. striatus but preferred by $N$. minimus, whereas A. saccharum and $C$. cornuta was avoided by $N$. minimus but preferred by $T$. striatus. One solution to this problem would be to compare species using a different index, such as one for differentiation diversity ( $\beta$ diversity; Maurer \& McGill, 2011).

There are other potential applications of this approach to understand foraging decisions. The greatest strength of using diversity indices to quantify foraging choices is that these indices account for both number of different food types consumed and the proportion in which they are consumed simultaneously. In cases where foragers sample every food type offered, investigators can focus solely on evenness. Another strength of this approach is that it is unlimited in terms of loss of statistical power by the number of different resources that can be tested simultaneously. Moreover, the variation in index values can aid in further testing. For example, the variability in index values was greater for T. striatus, indicating that this species consumed different amounts of resources relative to $N$. minimus. Another application incorporates testing hypotheses when the total amount of each resource is not equal. The amounts of each resource can be varied without loss of discriminatory power. In other words, this approach allows for behavioral titrations, in which amounts of each resource can be modified to test hypotheses concerning how resource availability affects foraging decisions. For example, future studies can test the strength of preference for A. rubrum seeds by $N$. minimusby altering the amount of $A$. rubrum seeds relative to other seed types.

Preferences for seeds by each chipmunk species clearly matched differences in body size. The smaller-bodied N. minimus preferred the small seeds of A. rubrum, whereas T. striatusconsumed more of the larger seeds of $A$. saccharum and C. cornuta. This result is consistent with the concept of size assortment, which has been documented in other speciose rodent communities (Brown \& Lieberman, 1973; Emmons, 1980; Brown \& Bowers, 1984; Ivan \& Swihart, 2000). Size assortment is a mechanism to reduce interspecific competition pressures. Chipmunks are well-known to be aggressive toward other species and are cited as a textbook example of how interspecific competition can structure communities (Chappell, 1978). Thus, the finding of size assortment between these species is consistent with limiting similarity and is not surprising.

Preferences within each individual chipmunk species can be interpreted using optimal foraging theory. The smaller $N$. minimus may avoid larger seeds such as $C$. cornuta and A. saccharum not only due to competition with $T$. striatus but also because large seeds have a longer handling time relative to reward. This is a more likely explanation than direct interference competition, as each individual was able to forage freely during the trials. A. rubrum is a common seed found in this system and is preferred by other rodents such as deer mice (Peromyscus maniculatus gracilis ) presumably because their seed coat is thin, thus reducing handling time (Cramer, 2014). P. pensylvanica, also comparable in size, has a tough seed coat, and may be avoided by $N$. minimus for this reason.

Both chipmunk species avoided consumption of $A$. balsamea, a result consistent with studies that have shown that seed predators in general and Peromyscus maniculatus and Myodes(=Clethrionomys ) gapperi specifically avoid consumption of A. balsamea seeds (Abbott, 1962; Lobo, 2014). Consumption of A. balsamea seeds by chipmunks has not been tested explicitly. Presumably, seed predators avoid fir seeds because they contain a high proportion of distasteful plant secondary compounds (Rubino et al., 2012). Another potential reason for low consumption of $A$. balsamea in this study centers on seed presentation. In nature, sciurids are known to collect conifer seeds while they are still in cones, for easier and more efficient transport to seed middens (Smith, 1970). In this study, fir seeds were presented without cones, and foragers may have viewed individual seeds encountered in this manner as not worth the effort.

Analysis of T. striatus foraging preferences uncovered an interesting relationship. Overall, these largebodied chipmunks preferred the seeds of larger species, A. saccharum and C. cornuta, in concordance 
with other studies of foraging preferences. However, closer examination of individual chipmunk preferences exposed a significant negative correlation between amount of $C$. cornutaconsumed compared to amount of A. saccharum consumed (Kendall's rank correlation: $T=26, P=0.04$, tau $=-0.43$ ). This suggests that individuals decided to consume either hazelnut or maple, but not both. Although this result is preliminary and based on a relatively small sample size $(\mathrm{n}=14)$, it could have serious ramifications on the interpretation of foraging preferences because of the suggestion that preferences can vary among individuals. More detailed data collection will determine the ubiquity of this observation. For example, it is possible that individuals that showed a preference for hazelnut over maple are simply those that had encountered hazelnut in the past, or even those that sampled the hazelnuts first at the start of the trial. As total amounts eaten were measured, and not the order in which seeds were sampled, the data reported herein cannot definitively address this question.

Ultimately, chipmunk species composition is changing in the Great Lakes region. Myers, Lundrigan, Hoffman, Haraminac, and Seto (2009) have demonstrated a decrease in $N$. minimus and an increase in $T$. striatus populations in the Great Lakes. They attribute this to a concomitant widespread increase in average minimum temperature of $2.1^{\circ} \mathrm{C}$. This potential shift in abundances between chipmunk species could alter forest composition through differences in seed preferences and caching behavior.

\section{Conclusions}

Use of the Shannon Index of diversity and evenness allowed interpretation of feeding trial data for two potentially competing chipmunk species. The versatility of diversity indices allows for simultaneous assessments of cafeteria-trial data that is not restricted by the number of different choices offered. In addition, behavioral titrations can be conducted to assess the effects of varying frequency of specific food items on foraging preferences. Finally, this approach is not reliant on consumption curves and does not suffer from some of the statistical shortcomings of conducting all possible pairwise comparisons.

This approach yielded insights into resource utilization in the small mammal community. Food choices by foraging chipmunks reflect body size, with the smaller $N$. minimus consuming small-seeded $A$. rubrum whereas larger $T$. striatus preferred tree species with the largest seeds (A. saccharum and $C$. cornuta ). This is consistent with studies of rodent granivores in other systems. An unexpected result concerned individualistic foraging preference: individual $T$. striatus preferred either $A$. saccharum or C. cornuta, but not both. This implies variation in individual response to foraging options and merits further attention.

\section{Acknowledgments .}

The authors would like to thank Ashleigh O'Reilly, Camille A. Berrocal, Maggie Wisniewska, Luke DeGroote, Riley Parrot, and Cayla Bendel for assistance in the field. The collection of data was completed during the Practicum for Field Environmental Biology course at the University of Notre Dame Environmental Research Center and was also an undergraduate thesis for AL in the Glynn Family Honors Program at the University of Notre Dame. All use of wild animals was approved by the Institutional Animal Care and Use Committee at the University of Notre Dame (protocol \#14-047) and by the Department of Natural Resources for both Wisconsin (SRL-NOR- 026-0409) and Michigan (SC 1168). Funding was provided by the Bernard J. Hank Family Endowment to the University of Notre Dame. None of the authors have any conflicts of interest to declare.

\section{Author Contribution Statement}

All authors contributed to the conceptual development of the project; AL, SD, and DGF collected the data; AL and MJC conducted the analyses; AL and MJC led the writing of the manuscript. All authors contributed critically to the drafts and gave final approval for publication.

\section{Data Availability}

Data will be made available from the Dryad Digital Repository. Authors are in the process of uploading data for this project and obtaining DOI. 


\section{References}

Abbott, H. G. (1962). Tree seed preferences of mice and voles in the northeast. Journal of Forestry, 60, 97-99. doi: $10.1093 /$ jof $/ 60.2 .97$

Brown, J. H., \& Bowers, M. A. (1984). Patterns and processes in three guilds of terrestrial vertebrates. In D. R. Strong, D. Simberloff, L. G.Abele, \& A.B. Thistle (Eds.), Ecological communities: conceptual issues and the evidence (pp. 282-296). Princeton, NJ: Princeton University Press.

Brown, J. H., \& Lieberman, G. A. (1973). Resource utilization and coexistence of seed-eating desert rodents in sand dune habitats. Ecology, 54, 788-797. doi: 10.2307/1935673

Chappell, M. A. (1978). Behavioral factors in the altitudinal zonation of chipmunks (Eutamias ). Ecology, 59, 565-579. doi: 10.2307/1936586

Cramer, M. J. (2014). Seeds of doubt: feeding preferences of white-footed deer mice (Peromyscus leucopus noveboracensis) and woodland deer mice (Peromyscus maniculatus gracilis ) on maple (genus Acer ) seeds. Canadian Journal of Zoology, 92, 771-776. doi: 10.1139/cjz-2014-0090

Curtis, J. (1959). The vegetation of Wisconsin. Madison, WI: University of Wisconsin.

Dostaler, S., Ouellet, J-P., Therrien, J-F., \& Côté S. D. (2011). Are feeding preference of white-tailed deer related to plant constituents? The Journal of Wildlife Management, 75, 913-918. doi: 10.1002/jwmg.118

Elston, D. A., Illius, A. W., \& Gordon, I.J. (1996). Assessment of preference among a range of options using $\log$ ratio analysis. Ecology, 77, 2538-2548. doi: 10.2307/2265752

Emmons, L. H. (1980). Ecology and resource partitioning among nine species of African rain forest squirrels. Ecological Monographs, 50, 31-54. doi: 10.2307/2937245

Ethical and Animal Care Committee of the Animal Behavior Society. (2012). Guidelines for the treatment of animals in behavioural research and teaching. Animal Behaviour, 83, 301-309. doi: 10.1016/j.anbehav.2011.10.031

Hsia, J. F., \& Francl, K. E. (2009). Postdispersal sugar maple (Acer saccharum ) seed predation by small mammals in a northern hardwood forest. The American Midland Naturalist, 162, 213-223. doi: 10.1674/00030031-162.2.213

Ivan, J. S., \& Swihart, R. K. (2000). Selection of mast by granivorous rodents of the central hardwood forest region. Journal of Mammalogy, 81, 549-562. doi: 10.1644/1545-1542(2000)081<0549:SOMBGR>2.0.CO;2

Jenkins, J. R., \& Devenport, L. D. (2014). Seed preparation diminishes cache loss in least chipmunks. Journal of Mammalogy, 95, 276-83. doi: 10.1644/13-MAMM-A-123

Krebs, C. J. (1999). Ecological methodology (2 ${ }^{\text {nd }}$ ed.). Menlo Park, CA: Benjamin/ Cummings.

Lobo, N. (2014). Conifer seed predation by terrestrial small mammals: a review of the patterns, implications, and limitations of top-down and bottom-up interactions. Forest Ecology and Management, 328, 45-54. doi: 10.1016/j.foreco.2014.05.019

Lobo, N., Duong, M., \& Millar, J.S. (2009). Conifer-seed preferences of small mammals. Canadian Journal of Zoology, 87, 773-780. doi: doi.org/10.1139/Z09-070

Lobo, N., Green, D. J., \& Millar, J. S. (2013). Effects of seed quality and abundance on the foraging behavior of deer mice. Journal of Mammalogy, 94, 1449-1459. doi: 10.1644/12-MAMM-A-295.1

Maurer, B. A., \& McGill, B. J. (2011). Measurement of species diversity. In A. E. Magurran \& B. J. McGill (Eds), Biological diversity: frontiers in measurement and assessment (pp. 55-65). Oxford, UK: Oxford University Press. 
Meiners, S. J., \& Stiles, E. W. (1997). Selective predation on the seeds of woody plants. Journal of the Torrey Botanical Society, 124, 67-70. doi: 10.2307/2996599

Morrison, S.F., \& Hik, D. S. (2008). Discrimination of intra- and inter-specific forage quality by collared pikas (Ochotona collaris ). Canadian Journal of Zoology, 86, 456-461. doi: 10.1139/Z08-023

Myers, P. B., Lundrigan, L., Hoffman, S. M., Haraminac, A. P., \& Seto, S. H. (2009). Climate-induced changes in the small mammal communities of the northern Great Lakes region. Global Change Biology, 15, 1434-1454. doi: 10.1111/j.1365-2486.2009.01846.x

Neu, C. W., Byers, C. R., \& Peek, J. M. (1974). A technique for analysis of utilization-availability data. The Journal of Wildlife Management, 38, 541-545. doi: 10.2307/3800887

Page, K. L., Swihart, R. K., \& Kazacos, K. R. (2001). Seed preferences and foraging by granivores at raccoon latrines in the transmission dynamics of the raccoon roundworm. Canadian Journal of Zoology, 79, 616-622. doi: 10.1139/z01-024

Penner, J. L., \& Devenport, L. D. (2011). A comparative study of caching and pilfering behavior in two sympatric species, least chipmunks (Tamias minimus) and eastern chipmunks (Tamias striatus). Journal of Comparative Psychology, 125, 375-384. doi: 10.1037/a0024562

R Core Team (2019). R: A language and environment for statistical computing. R Foundation for Statistical Computing, Vienna, Austria. URL https://www.R-project.org/

Rice, W. R. (1989). Analyzing tables of statistical tests. Evolution, 43, 223-225. doi: 10.1111/j.15585646.1989.tb04220.x

Rubino, F. M.., Martinoli, A. l., Pitton, M., Di Fabio, D., Caruso, E., Banfi, S., Tosi, G., Wauters, L. A., \& Martinoli, A. D. (2012). Food choice of Eurasian red squirrels and concentrations of anti-predatory secondary compounds. Mammalian Biology, 77, 332-338. doi: 10.1016/j.mambio.2012.01.003

Schnurr, J. L., Canham, C. D., Ostfeld, R. S., \& Inouye, R. S. (2004). Neighborhood analyses of smallmammal dynamics: impacts on seed predation and seedling establishment. Ecology, 85, 741-755. doi: $10.1890 / 02-0644$

Sih, A. (2011). Foraging theory. In S. M. Scheiner \& M. R. Willig (Eds.), The theory of ecology (pp. 65-90). Chicago, IL: The University of Chicago Press.

Sikes, R. S, \& Gannon, W. L. (2011). Guidelines of the American Society of Mammalogists for the use of wild mammals in research. Journal of Mammalogy, 92, 235-253. 10.1644/10-MAMM-F-355.1

Smith, C. C. (1970). The coevolution of pine squirrels (Tamiasciurus ) and conifers. Ecological Monographs, 40, 349-371. doi: 10.2307/1942287

Snyder, D. (1982). Tamias striatus. Mammalian Species, 168, 1-8. doi: 10.2307/3503819

Stephens, D. W., \& Krebs, J. R. (1986). Foraging theory. Princeton, NJ: Princeton University Press.

Thomas, D. L., \& Taylor, E. J. (1990). Study designs and tests for comparing resource use and availability. The Journal of Wildlife Management, 54, 322-330. doi: 10.2307/3809050

van Emden, H. (2008). Statistics for terrified biologists ( $1^{\text {st }}$ ed.). Oxford, UK: Blackwell Publishing.

Vander Wall, S.B., \& Jenkins, S. H. (2011). Plant-animal interactions and climate: why do yellow pine chipmunks (Tamias amoenus ) and eastern chipmunks (Tamias striatus ) have such different effects on plants? Ecoscience, 182, 130-137. doi: 10.2980/18-2-3375

Verts, B. J, \& Carraway, L. N. (2001). Tamias minimus. Mammalian Species, 653, 1-10. doi: 10.1644/15451410(2001)653\%3C0001:TM\%3E2.0.CO;2 
Wang, B. C., \& Smith, T. B. (2002). Closing the seed dispersal loop. Trends in Ecology \& Evolution, 17, 379-385. doi: 10.1016/S0169-5347(02)02541-7

Wang, L., Wang, D., Liu, J., Huang, Y., \& Hodgkinson, K. C. (2011). Diet selection variation of a large herbivore in a feeding experiment with increasing species numbers and different plant functional group combinations. Acta Oecologica, 37, 263-268. doi: 10.1016/j.actao.2011.02.010

Warton, D. I, \& Hui, F. K. (2011). The arcsine is asinine: the analysis of proportions in ecology. Ecology, 92, 3-10. doi: 10.1890/10-0340.1

Woods, B. C. (2009). Using multivariate techniques to determine if yellow-bellied marmots feed selectively. Ethology Ecology \& Evolution, 21, 261-276. doi: 10.1080/08927014.2009.9522481

Ydenberg, R. C., Brown, J. S., \& Stephens, D. W. (2007). Foraging: an overview. In D. W. Stephens, J. S. Brown, \& R. C. Ydenberg (Eds.),Foraging behavior and ecology (pp. 1-28). Chicago, IL: University of Chicago Press.

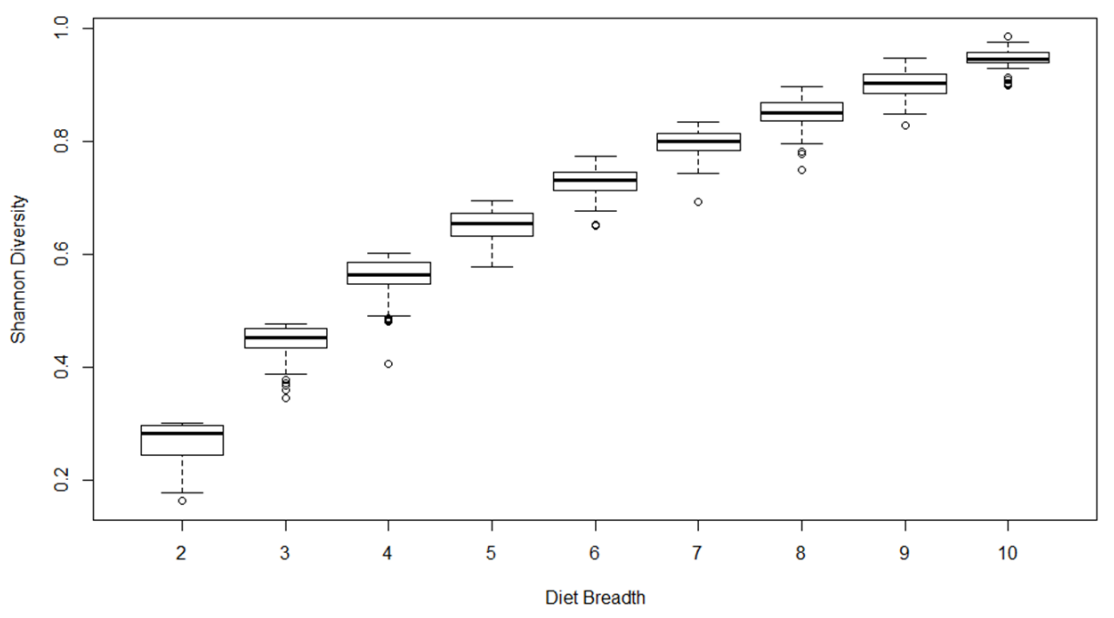



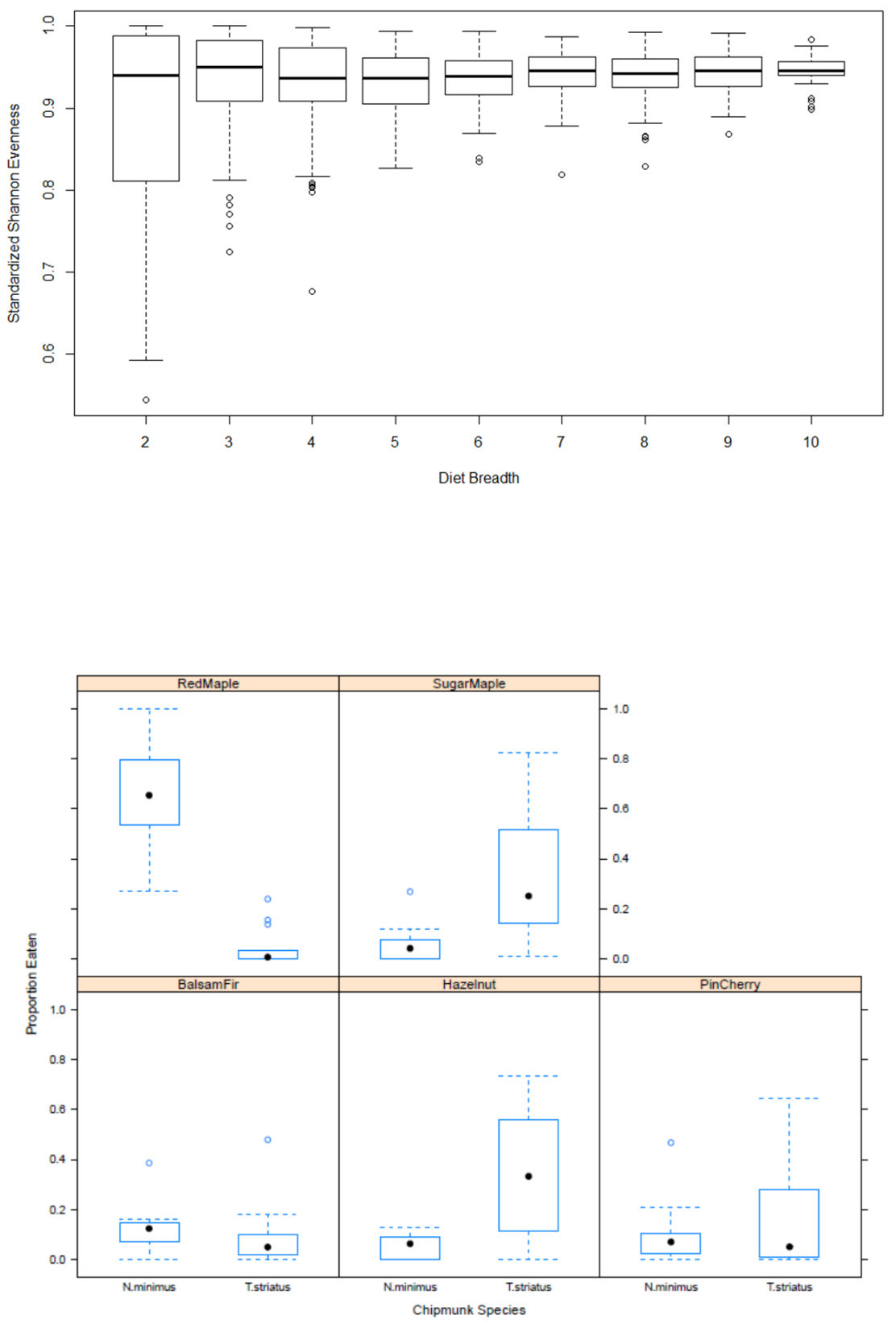